\title{
A CONCEPTUAL FRAMEWORK OF MANAGEMENT DEVELOPMENT PROCESS IN THE MAURITIAN HOTEL SECTOR BASED ON THE GROUNDED THEORY APPROACH
}

\author{
Needesh Ramphul \\ University of Technology Mauritius \\ Hemant Chittoo \\ University of Technology, Mauritius \\ Tegshbuyan Munkbat \\ National University of Mongolia
}

\begin{abstract}
Managers have a vital role to play in ensuring quality and efficiency of service in the hotel sector in general. Effective Management development programmes and processes ensure that hotels have the right quantity and quality of managers that they need in order to be competitive and achieve their objectives especially in a very competitive and fast changing business environment. However, few studies have been carried out to understand the actual process of developing managers within the hotel sector in Mauritius from the perspectives of participants of the management development programmes. The purpose of this paper is to understand the way in which management development process operates within the Mauritian hotel sector. A grounded theory approach was used since little research has been carried out on this aspect in Mauritius. In this context, 25 participants (resort managers, reservation managers, finance managers, front office managers, room service managers and food and beverages managers) from Mauritian hotels were interviewed to get relevant information on the management development process. The data was analysed using the Nvivo software. The research enables to come up with a new conceptual framework on the management development process based on the views of participants. The conceptual framework helps to understand the actual process of management development within the Mauritian context and it can help to compare with other models that exist in the hotel sector around the world.
\end{abstract}

Keywords: Grounded theory approach, Management development, Mauritian hotels, perspectives of participants

\section{Corresponding Author's Email Address: needesh.R@umail.utm.ac.mu}

\section{INTRODUCTION}

According to the World Travel and Tourism Council (2016), the travel and tourism sector has contributed to $9.8 \%$ of the world GDP in 2015 and it employs 286 millions of people across the world. The continued growth of the sector can only be sustained by having the right people with the right skills to meet the additional requirements in terms of human capital. This will also imply that hotels will also require additional managers having the appropriate competencies at different levels in order to achieve their objectives.

The Mauritian tourism sector is one of the main pillars of the Mauritian economy and it contributes a lot to the economic growth and development of the country. However, the sector has to face several 
challenges due to growing competition from other tourist destinations and financial problems in the European countries which are the main markets for the Mauritian hotel sector. The Mauritian hotels have been compelled to diversify their traditional markets and tap into emerging markets like India and China. However, for such strategy to be successful both line staff and managers have to develop new know how to better serve these new customers. On the other hand, the Mauritian government is trying to increase the number of tourist arrivals in future and this may also mean that expansion of the sector will lead to an increase in the demand for managers in the hospitality industry. Mauritian hotels spend lot of money on developing managers and they also have their own training academies for that purpose.

Lot of research have been carried out in the field of management development at the international context but very few research has been undertaken in Mauritius. The main purpose of this paper is to enable both academics and practitioners to better understand the actual way in which managers are being developed within the Mauritian hotel sector from the perspectives of the participants of the management development programs. A new conceptual framework will be developed from the interviews of participants in the hotel sector by using the grounded theory approach.

\section{DEFINITION OF MANAGEMENT DEVELOPMENT}

A review of the different definitions developed at different points in time helps to explain different views on the subject and, also, how the management development concept has evolved. This type of analysis was done by Cullen and Turnbull (2005). The common aspects of the various definitions are as follows:

- The definitions view managers as resources and management development as driven by a functional-performance rationale that emphasizes the improvement of management effectiveness and, as a result, corporate performance.

- The definitions emphasize that management development is a deliberate and planned activity driven by an organization's strategic orientation.

- Most definitions (particularly the earlier ones) view management development as being driven by organisational rather than individual needs.

They also note how only five definitions, all offered after 1985, mention learning. This general omission implies that most definitions do not claim that managers learn through their management development experience. Rather management development is "something that is done" to managers so as to improve their effectiveness. Modern authors recognise that management development is more than education and formal training and also includes informal learning through mentoring, coaching and on the job experiences. The definitions also highlight the continuous nature of management development for with organisations operating in dynamic environments, managers' competencies must be continuously upgraded.

All of the definitions view management development from an organisational point of view and overlook the fact that management development is important not only to organisations but also to industrial sectors and countries as a whole. Management development definitions should highlight consequences not only for organisations but also for a sector, an industry and even a whole country.

Recent definitions of management development believe that MD should enable the development of the manager as an individual and at the same time for the benefits of the organisation as well (CIPD, 2014). Another trend that has been observed is that the term leadership has been added with management 

definitions also recognise the importance of informal learning in building the skills, competencies and knowledge of managers.

\section{COMPETENCY FRAMEWORKS IN THE TOURISM SECTOR}

Competency models are being used to identify skills and Knowledge factors that are required in both hospitality and tourism education and operations (Chung-Herrera et al., 2003). They are also helping in identifying and developing important management skills so as to ensure the competitiveness and success of hospitality organisations in this fast changing business environment. Many studies have been conducted to identify key competencies of managers in the hospitality arena. Some have focused on technical skills, others on leadership and management skills and some on a balanced approach between these two. Some researchers have added new management competencies to the existing ones while others have identified management competencies required at different levels of management and future competencies that are required to be successful in the ever changing hospitality environment (Brownell, 2004; Chung-Herrera et al, 2003; Gilbert and Guerrier, 1997; Kay and Rusette, 2000)

A recent research done by Suh et al (2012) showed that there are six dimensions of core competencies that are important for the success of managers in the hospitality sector. The six dimensions include; hospitality skills, interpersonal skills, supervisory skills, food and beverages management skills, leadership and communication skills. Human resource skills are seen as a critical competency for hospitality managers (Brownell 2004; Suh,West J.and Shin J, 2012). The study carried out by Suh E., West J. and Shin J. (2012), confirmed the findings that human skills are one of the most important competency to be successful in the hospitality sector since interpersonal skills and supervisory skills were given higher ratings in terms of competencies required. Human skills also include ; leading teams, effective listening, coaching employees, providing feedback, managing conflicts, managerial communication, employee relations, training and organizing (Brownell, 2004; kay and Rusette, 2000). Another study showed that oral communication skills followed by leadership skills are the most important skills required to be a successful manager in the hospitality sector. (Gursoy and Swanger, 2005).However, Kay and Moncarz (2004) found that the most important skill is knowledge in financial management and compensation rather than human resource skills in the hospitality sector. They posited that people having knowledge in finance are better prepared for higher positions in the hospitality sector and they have higher chances of promotion. Recent research by Suth at al (2012) also confirmed hospitality skills as an important competency and in their research, knowledge in accounting and finance was a key component of hospitality skills.

According to Tiesta and Sipe (2012), managers will need to have three main competencies; Business Savvy, People Savvy and Self Savvy competencies to ensure service leadership in the hospitality sector. Business savvy competencies explored the different dimensions of the managers' behavior necessary to manage the business and the organization. People savvy competencies are competencies required to manage people in the hospitality sector. They are similar to Leadership behavior or people skills necessary to ensure develop positive interactions with others in the organization. People savvy competencies are important for both employee and customer satisfaction. Self-savvy competencies are competencies required at managing self in the service area and it can help improve personal effectiveness in providing better customer service. 
The competencies required by managers may also differ according to the level of management. According to a research, six competencies associated with human resource skills are the most important competencies required by hotel general manager trainees. They were; guest problem solving skills, ethical standards, professional appearance, communication skills, customer relation skills, and employee relations skills. Other management competencies included management functions like planning, leading, organizing, and controlling. According to the research, technical competencies like financial management, food sanitation and safety, room reservation and maintenance of guest room standards were considered less important. Technical skills are considered as less important since general managers can rely on technical specialists in case of technical problems. In other studies, middle level managers rated knowledge in information technology higher that upper level executives while upper level managers rated financial management as being more important when compared to middle level managers (Kay and Moncarz, 2004). General Managers rated professional appearance, poise and face to face communication more important than did lower level managers (Kay and Rusette, 2000)

An issue is the balance between the operational and managerial aspects of the hospitality management. It seems that operational skills are more important than management skills for middle and first line managers (Brophy and Keily, 2002). However, management skills are also vital for success in middle management positions. Ladkin and Juwaheer (2000), for example, point out how operational Food and Beverage knowledge and experience is important for being promoted in a general management position. For general managers, general business skills may be more important than operational/technical skills since tourism has becoming highly competitive and requires management like any other business (Harper et al, 2005). This implies that students and managers should develop business and management competencies and abilities including global exposure, an orientation to customer service, and an awareness of financial management issues, market trends, innovation in the industry, a commitment to work, leadership skills and an ability to adapt and change.

The context in which hospitality organisations are operating has drastically changed. Globalisation, increased competition and advancement in information technology has led to new expectations from stakeholders and hence leading to new competencies that will required from managers in future. Changes in the business environment has led to a shift of focus from operational skills to general business management skills (Suh,West J.and Shin J, 2012). Recent research has shown that situational flexibility followed by team building and problem solving skills are the most important skills required by future managers in the hospitality sector. (Suh,West J.and Shin J, 2012). Human skills like interpersonal relationship, leadership, communication, empowerment, staff motivation are still an important competency to be successful in future and more strategic business management skills will be required by top managers in the hotel sector to deal with new challenges facing the industry.

\section{MANAGEMENT DEVELOPMENT IN THE TOURISM SECTOR}

Management advancement is considered to be an outcome of management development and hence, it will influence the content of management development programs. Garavan et al (2006) considered "investment in training and education, mentoring, networking, experience and competencies, and individual commitment to advancement as being important in enhancing careers." Career mobility in addition to international experience and international qualifications are also important for acquiring general management positions in the hotel industry (Ladkin and Jawaheer, 2000). 
Harper et al (2005) found that there is a reduction in the emphasis on food and beverage knowledge that is required in order to get general management positions in the hotel industry. Managers having management qualifications, for example, achieve general management positions more quickly than those without such qualifications. On the other hand, the importance of food and beverage knowledge and knowledge in other technical areas is still important for getting general hotel management positions (Garavan et al, 2006, Ladkin and Jawaheer, 2000). Many hospitality graduates take first line management or supervisory positions in order to get the needed knowledge and experience and with time, they hope to develop their career either within the particular hotel or outside it (Ladkin, 2000). These issues affect the design of management development programs as having appropriate content including general management and technical aspects reflective of local situations can help motivate managers to participate. Then, management development programs can be seen as way to meet career development objectives for sector managers.

In the hospitality industry, management development occurs at the start of a career in the sector and it is usually not well-organised and done on a piece-meal basis (Watson, 2008). Moreover, management development practices are closely linked to business goals and objectives. Performance appraisal and assessment centers are also widely used to determine the management development needs. The evaluation of management development practices is mainly done to show the benefits of the process to the individual (in terms of career advancement) and to organization (in terms of achieving business objectives). However, it is difficult to evaluate the immediate impact of management development on an organization or what the long term benefits may be. There is a firm belief that experiential learning is the best way to develop managers and have them learn directly from their work environment. There is an emphasis on action learning to support collaboration between educational institutions and the hospitality sector and industry.

\section{RESEARCH METHODOLOGY}

\section{Qualitative Research Methodology}

A qualitative method was used for the purpose of this research. This method was most appropriate for this research since there were few researches done on this subject especially in Mauritius and within the hotel sector. Another reason for using such a methodology was that there were no hypotheses to test but instead, the research tried to identify relevant variables that may be important in a particular situation and generate new ideas and theories (Eisenhart, 1989). Consequently, this research can be used to formulate relevant hypothesis for future research. The research also tries to learn from the experience of informants in a specific context and the way they experience and the meanings that they put the management development process and this also make it more appropriate to use the qualitative approach (Morse and Morse, 2002). Qualitative approach has many methods and in this case, the grounded theory approach was used to satisfy the research objectives.

The grounded theory approach was more relevant since the aim of the research is to find the meaning attributed to a situation by groups of individuals (Strauss and Corbin, 1998). According to them, the theory that is derived from the data collected from the field, explains how a phenomenon actually takes place than when using other peoples concept or speculation about a specific situation. This enables to build a conceptual model from the data gathered in order to understand the management development process from the perspectives of the both informants who experience the process from different point of views. The whole conceptual comes from the data gathered both through the interviews and the secondary data collected from annual reports and government statistics. 
There are three main versions of the grounded theory approach. The first one is that of Glaser and Strauss(1967), the second one is that of Strauss and Corbin(1998) and the third one is associated with the work of Chamaz(2006). According to Glaser, the researcher under the grounded theory approach should not do a literature review first since it will influence the theory building process. According to him, the theory has to be completely derived from the data collected on the field. He also disagreed to the fact that the research will have prior research questions since research questions and problems are discovered when the data is being coded. However, Strauss and Corbin (1998) do not agree with the views of Glaser (1967) since they believe that the researcher should have some exposure to the literature as they can refer to it when the need arises. In addition, Strauss and Corbin (1998) think that prior research questions have to be developed as they can set boundaries to the study area. For the purpose of this study the version developed by Strauss and Corbin (1998) has been used since I reviewed the literature of Management development in General and within the hotel sector and based on the research Gap, research questions have been developed. The research questions effectively set the boundaries under which the whole study has been carried out. Moreover, the analysis of the data gathered was done according to the process proposed by Strauss and Corbin (1998). According to Chamaz (2006), the grounded theory approach is a constructivist approach rather than an interpretive approach since as the research advances a model is being constructed by the researcher. To some extent, the model was constructed based on the interview scripts provided by the informants. However, the research was to a large extent influenced by the work of Strauss and Corbin (1998).

\section{Informants}

First-line, middle, and top level managers are all potential participants in hotel sector management development programs. Apart from traditional functional management roles, management development program participants included front office managers, reservation managers, food and beverage managers, and resident and entertainment managers. All hotel sector managers represented target groups for management development programs. The perspectives of the participants of the management development in the Mauritian hotels helped to understand different aspects related to the management development process.

\section{Population}

The population defines a set of characteristics from which a research sample is drawn (Eisenhardt, 1989). In addition, the population defines limits for the generalization of any findings. For the purposes of this research, the relevant population included the participants in management development programs in the different hotels in Mauritius .

\section{Sample Size and Theoretical Sampling}

Sampling from a population when one is pursuing grounded theory is different from sampling from a population when one is seeking to test hypotheses. In particular, the emphasis is on theoretical sampling rather than random sampling. According to Glaser and Strauss (1967), when one pursues grounded theory, one chooses cases for theoretical reasons, i.e., to make sure all of the characteristics in the population are represented in the sample. The aim, then, is to make sure all theoretical categories and polar types from the population are included in the sample (Eisenhardt, 1989). For example, theoretical sampling dictates that the researcher chooses participants who have directly experienced the phenomena under study. By proceeding in this way, the researcher includes relevant 'experts' who are able to provide the best data available (Corbin \& Strauss, 1998; Glaser \& Strauss, 1967). The process 
of selecting participants is also an evolving process based on the evolving patterns, categories and dimensions that emerge as a result of gathering data. Specifically, researchers seek out participants who can provide deeper insights into the emerging patterns, categories and dimensions that become apparent in the sampling process. The same process was used in the context of this study and the data collected was analysed at the same time as the research progressed so that new themes, categories can be identified and verified with other people selected as the sample for the study. Although there is no definite sample size in the Grounded theory approach ,25 participants (i.e,first line/ middle managers) in the hotel sector have been interviewed after theoretical saturation was reached as no new categories or subcategories emerged after these 25 interviews were carried out.

\section{Interview}

The main tool for primary data collection was an in-depth interview. The interviews were audio taped after informants gave me permission to do so. Audio taping was necessary since it would be very difficult to take sufficient notes to record everything informants say concerning their perspectives on management development. It also enabled to maintain good eye contact with the informants and to respond appropriately if difficulties emerge. Audio taping also helped in the analysis after the interview for the taped record ensured that no important data was missed out. The duration of all the interviews was between 30 minutes to one hour and most of the interviews were carried out in the hotels where the participants were working. The contents of the interview were transcribed verbatim so as to be able later to identify categories that informants used to explain their perspective. This is in line with the suggestions of Glaser and Strauss (1967) who argue for collection, coding and analysis of data concurrently.

\section{Data Analysis}

In a grounded theory study, the researcher concurrently collects and analyzes the data (Glaser and Strauss, 1967; Miles and Huberman, 1994). This ongoing process enables the researcher to constantly identify emerging themes, issues that need further probing in future interviews and to confirm or reject emerging themes. In addition, this process also determines when one reaches a point of theoretical saturation. According to the grounded theory approach (Strauss and Corbin, 1998), data analysis is performed through a continuous coding process and there are three main types of coding namely Open, Axial and Selective coding.

\section{Open Coding}

First, an open coding of the data is performed. At this stage, the data gathered from the field was analysed line by line in order to identify relevant themes and categories relevant to the management development process as it actually occurs in the Mauritian hotels. All the transcripts pertaining to different aspects of the management development process of the participants were analysed line by line using the NVivo 8 software and appropriate codes were allocated to each relevant aspects of the interview transcripts. The codes that were identified will represent concepts that will later become part of the theory.

\section{Axial Coding}

The second aspect of the analysis under the grounded theory approach is known as axial coding. In axial coding, the data is analysed to see the relationship and links between the different categories/themes that were developed after the open coding process. In this context, the links between 
the different types of categories and themes that come for management development process in the Mauritian hotel sector were analysed.

\section{Selective Coding}

The coding process continues with selective coding. Selective coding aims at identifying the core category around which the theory will be built. The core category will act as the reference to all the other identified categories and it must be central in that all the other categories must relate to it and hence it must frequently appear in the data. Selective coding also tries to further develop categories into a theory since they merely describe the data that have been collected.

\section{DISCUSSION}

After the open coding process, the relationship between the different open codes has been determined from the interviews of the participants. It is suggested to use a model so as to analyse the links between the different codes and the model includes the following aspects; causal conditions, the phenomenon itself, the context, intervening conditions, action/interaction strategies, and consequences (Strauss and Corbin, 1998). The causal conditions explain the factors that influence and lead to the central phenomenon. The phenomenon tries to explain the question about what is going on here? and what are the incidents, actions, and interactions that surrounds the phenomenon? It also looks into the people who are involved in the process, and how these people manage, influence and relate to the phenomenon. In the context, we try to look at the locations of events and where the phenomenon takes place. It also considers the time and stage at which the phenomenon can occur. On the other hand, the intervening conditions represent the actions that the people need to perform and this will help to shape and facilitate the strategies. Strategies represent the ways in which people address the phenomenon. They are usually purposeful and goal oriented. It is the strategies that help to achieve the outcomes and helps to meet the objectives that were set. The last part of the model will usually represent the consequences and these will represent the results of the actions and interactions and the outcomes of the strategies that were used. The following diagram represents the model that was developed after carrying out the axial coding process for the management development process in the Mauritian hotel sector from the perspectives of participants.

\section{Causal Conditions}

The causal conditions explain the different factors that lead to the main phenomenon. In this case, 23 out of 25 participants' voice out that designers will usually monitor their weaknesses and future requirements of their jobs in order to design the management development programs in the hotels. Their development plans are discussed with the direct superiors and the designers of management development programs in the hotels during performance appraisal and this is part of the performance system management in different hotels. This is in line with the views of Byar and Rue (2006) who state that performance management systems can help to identify the developmental needs of managers in an organization. This will usually lead to the design and the implementation of the management development programs in most of the Mauritian hotels. In addition, the views of the participants are taken on board while the designers are carrying out the development needs analysis in the Mauritian hotels. The participants get the opportunity to highlight their development needs to the designers. Management development objectives will also influence the different ways in which managers will be developed in Mauritian hotels. On the other hand, the management objectives will also impact on the motivation of the participants of these programs. For instance, if career development opportunities and increase in performance bonus are related objectives of the development programs then most of the 
International Journal of Research in Management

ISSN 2249-5908

Available online on http://www.rspublication.com/ijrm/ijrm_index Issue 8, Vol. 3 (April-May 2018)

participants will be highly motivated to take part in the programs. 10 out of 25 participants view management development as a means of personal development (Jansen and Mul, 2001). Participants should also have knowledge about the different development opportunities that are available within the different hotels in Mauritius. This will enable them to actively participate in them. Moreover, the management objectives should also be communicated to them during the communication process.

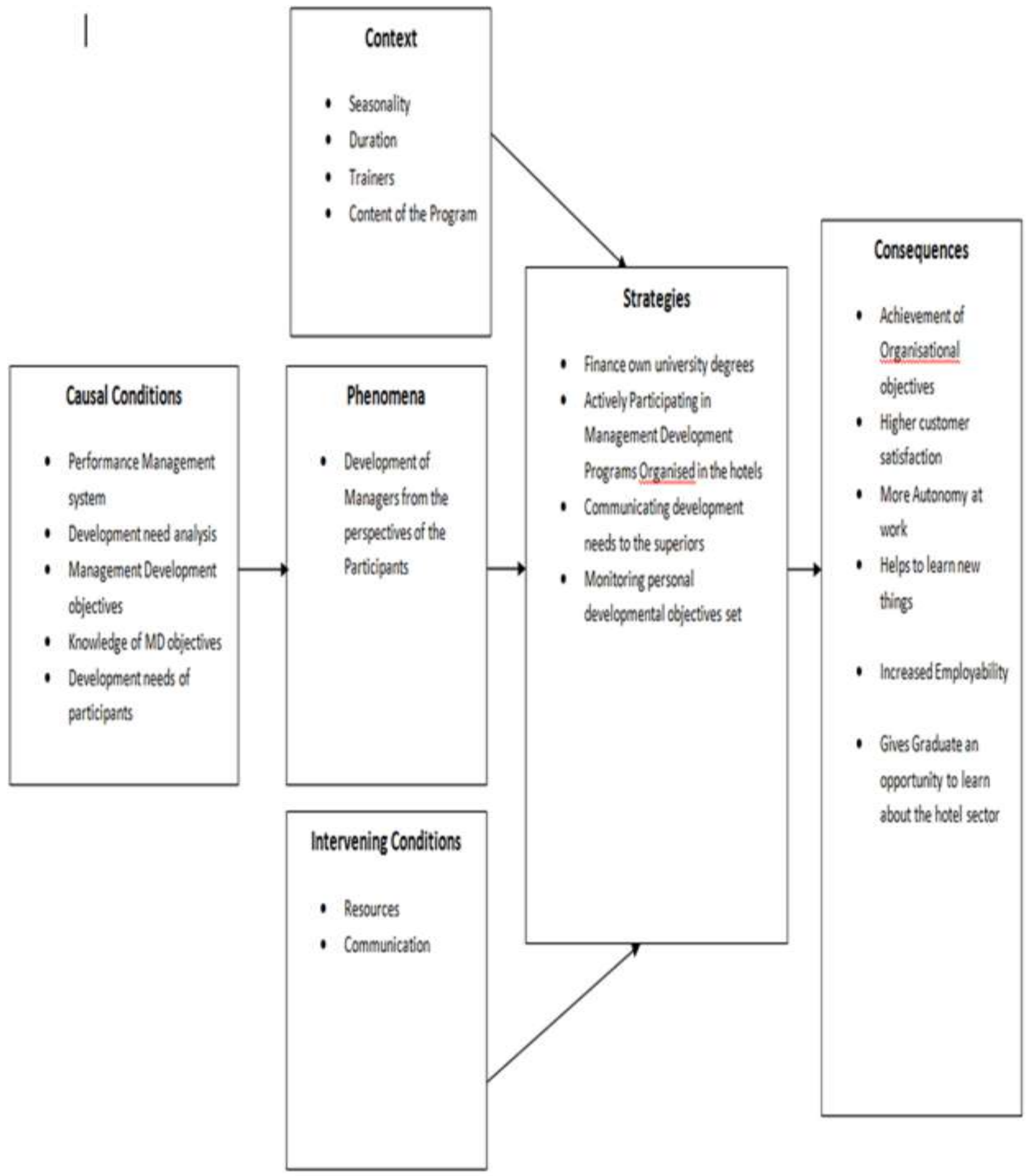




\section{Main Phenomenon}

The main phenomenon in this context is the different aspects related to the management development process from the perspectives of the participants in the Mauritian hotel sector. Participants have development needs and they can usually communicate it to the designers or their direct superiors in their respective hotels. Management development programs are organized so as to meet the development needs of both the participants and the organizations. In the Mauritian hotel sector, development needs are also identified through the feedback from customers and this will usually help to increase customer satisfaction and achieve organizational objectives. Different stakeholders are involved in the management development programs within the Mauritian hotel sector and they may include; top managers, designers, participants, evaluators (mystery shoppers, customers), mentors, coaches, development experts amongst others (Thomson A et al, 2001). Participants may have different perspectives on the management development process itself. Some participants believe that continuous improvement is always possible at work and they must continuously upgrade their knowledge and skills since the world of work continuously changes. On the other hand, some participants are not motivated to participate in the management development program since they believe that they have achieved their full potential and they are content with their actual situation. Managers who have started their career at a very low level and they have become managers through internal promotion in the hotel will usually hold such beliefs. They may view the management development programs as an additional burden to their work. Another divergent view among participants is that management development programs have to be initiated by the organization whereas others feel that they are responsible for their own development and hence they will take individual initiatives to ensure proper development of their management skills and knowledge. According to Mabey (2005), participants are more willing to participate in management development programs if they see that top management is committed towards the process. For instance, some participants may decide to follow university degrees so as to gain additional knowledge and qualifications to improve their management know how and at the same time improve their employability on the labour market.

\section{Context}

The context in which the management development process is taking place is very specific and it impacts on the way the whole process occurs. For all the participants, the seasonality of the Mauritian tourism sector is a very important factor that affects the management development process. This is in line with the views of Mabey and Thomson (2000) who state that the sector in which an organization operate affects the whole management development process. Participants will usually prefer to have formal management development programs during the off peak period since they have less involvement in the operations of the hotels and they can concentrate on the management development programs. They have voiced out such concerns while analyzing the different aspects that they dislike in the management development programs. They usually prefer management development programs whose duration is not too long especially when the management development programs have a strong theory component. They like management development programs which are more practical. Trainers have also an important role to play in making management development programs become more effective. The choice of the trainers will depend on the different types of participants. For instance, experienced managers will usually act as mentors or coach for new managers or fresh graduates of universities in order to develop future managers for the Mauritian hotel sector. Experienced managers who have been promoted through good performance at lower level may lack some managerial skills in broad management areas like; finance, human resource, team building, leadership amongst others and they must be assigned trainers who can develop them on these short comings. 


\section{Intervening Conditions}

The intervening conditions will usually consist of prior conditions which need to be accomplished before the strategies are adopted. 13 out of 25 participants of the management development programs believe that they can take their own initiatives when it comes to developing their skills and know how. Participants may decide to follow courses at the university so as to improve their job prospects in the future. However, they will need to secure prior finance to pay for university fees. In some cases, in Mauritius, they must also seek permission from the top management in the Mauritian hotels to follow such courses as it may have some implications on the operations of the hotels. Consequently, resources are very important for the participants before adopting such initiatives. Another aspect which must be carried out before using any management development strategies is prior communication about the importance and value of the management development programs that are run in the Mauritian hotels. From the interview scripts, we have seen that not all participants will be motivated to follow the management development programs organized by the hotels since they believe that they have achieved their full potential and they do not need to learn any further. Communication about management development programs in the Mauritian hotels enables the participants to know more about the content and the objectives of these programs. In some Mauritian hotels, participation in management development programs is compulsory since it is linked to the performance rating of the managers and such expectations must also be communicated to the participants in these hotels.

\section{Strategies}

Strategies help us to understand the way in which the participants ensure their development in the Mauritian hotels. It has been found that some participants will take their own initiatives when it comes to their development and hence they may decide to finance their own university degrees which may be important for promotion within the same hotels or getting better job prospects on the external job market. In some cases, the Mauritian hotel may finance the university degree for them but the participant will have to give extra efforts to complete the university degrees. These participants take their own responsibility for further development rather than wait for the organization to come up with management development programmes. This meets the idea of Peter Drucker (1955) who believes that the individual must be responsible for his own development rather than the organization. 13 out of 25 participants are of this view that the responsibility for development should be self-development and personal initiatives.

Many participants voice out that they will also follow management development programs that are organized in their respective hotels. Such participations help them to get additional skills and know how about their respective jobs. Moreover, this also encourages sharing of ideas from other managers working in same chain of hotels. In addition, they can communicate their development needs to their superiors or designers so that relevant and job related development programs can be designed in their respective hotels.

Participants also follow up on the developmental objectives that they set for themselves. They monitor the degree to which they are able to achieve the objectives that they have set and the different actions that they can take in case they are behind their objectives. Participants ensure that they have the update skills, knowledge and experience required for the efficient completion of their job.

\section{Consequences}

The consequences will usually show the impact of the strategies adopted on the participants of the 
management development programs in the Mauritian hotel sector. Participants believe that management development programs enable them to contribute in the achievement of organizational objectives through better efficiency and effectiveness. On the other hand, improved skills enable them to increase customer satisfaction within the Mauritian hotel sector. All the participants interviewed was of the opinion that management development in the hotel sector will help to achieve organizational objectives and improve customer satisfaction. These views confirm the findings of the research of Tiesta and Sipe (2012) who proposed different competencies to improve service leadership. Participants feel that they get more autonomy at work after following management development programs since they have the knowledge to tackle problems on their own and they do not have to look for assistance from their superiors. The management developments programs help managers to learn new developments in their respective operational areas and they are also aware about best practices in other hotels around the world. Participation in management development programs also help to improve the employability of the managers since they have higher education, better skills and knowhow which are valued on the external labour market. Some participants also voice out that management development programs provide an opportunity for graduates to learn about the hotel sector and develop their practical skills about the sector. Fresh graduates may have the academic knowledge about the hotel sector and it is only management development program that can enable them to get hand on experience about the sector. However only one of the participants raised this point with regards to management development objectives within the hotel sector. This will enable them to secure a management job in the Mauritian hotel sector. The management development programs are beneficial to the managers on a personal basis as well as for the organization.

\section{Selective Coding}

After the axial coding process, the core category(ies) was identified and it can explain the whole theory behind the theory developed for management development from the perspectives of participants. The core category for the participants is that their interest in MD programs is guided by personal objectives rather than organizational objectives. However, given that they are working in the hotel, they have to abide by their commitments towards the organization. Top management commitment towards MD programs in the organization can signal to line managers that their participation in MD programs is compulsory and they must necessarily attend these programs for the benefit of the organization and for their personal development. However, participants will be more motivated to follow the program if they see that the management development programs will help to develop their skills and competence in actual work and provide opportunities for promotion and even better career opportunities elsewhere. Some participants also view management development programs as a way to improve their actual performance at work and at the same time, enabling the organization their objectives through higher customer satisfaction. In some hotels, participation in MD programs and training is part of the appraisal process in order to get the performance bonus at the end of the year.

\section{Verification of Information in the models}

After the models was developed, it was shown to five of the people who were interviewed in the context of the research and other people who had lot of experience within the Mauritian Hotel sector. This was done to check whether it represented the actual process of Management development in the Mauritian hotels. Most of them agreed that the model reflected the actual process. They pointed out that the model help to understand the different perspectives of looking at the MD process in the Mauritian hotel. They also pointed out the importance of the seasonal factor which is prevalent in the Mauritian hotel sector and formal MD programs must be organized during off peak period rather than peak 
period. They also highlighted the importance of experiential learning as another major element of the development process and this can be continuous in nature.

\section{CONCLUSION}

This research helps to develop a conceptual framework of the management development process as it occurs within Mauritian hotel context by using the grounded theory approach. The conceptual framework was built based on the information that were provided by the participants of the management development programmes organized in their respective hotels in Mauritius. However, the grounded theory approach has got its own limitations as any other research methodology. One of the limitations of this research approach is that it depends a lot on the information provided by the participants of these management development programmes and sometimes, the latter just provide information that the researcher wants to hear and hence, the researcher may not capture the real practices as they occur in the real situations. This limitation can be overcome by looking for alternative sources of information on management development that may be available from annual reports of the hotel, documents from the designers of the management development programs and report from the government. While building the model, alternative sources of information have been considered and the model has been verified by other persons who have prior experience in the management development process in the Mauritian hotel sector. The model can be used to develop hypotheses that can be tested by using the quantitative research methodologies and the research can be carried out in other small island whereby the hotel sector plays a very important role in the economy to get a better insight about the management development process in the hotel sector.

\section{References}

I. Brophy, M and Keily, T. (2002), Competencies: a New Sector Analysis, Journal of European Industrial Training, Vol. 26, pp. 165-76

II. Brownell,J. (2004), Ingredients for success in career development, FIU Hospitality Review, 1-17

III. Chung Herrera et al (2003), Grooming future hospitality leaders ; A Competencies Model. Cornell Hotel and Restaurant Administration Quaterly, 44 (3), 17-25

IV. CIPD (2014), Factsheet on Management development, updated by CIPD staff, http://www.cipd.co.uk/hr-resources/factsheets/management-development.aspx accessed on 16 February 2016

V. Cullen John and Turnbull Sharon (2005), A Meta- Review of the Management Development Literature", Human Resource Development Review, Vol 4 No 3, pp. 335-355

VI. Drucker P. F. (1992), The Practice of Management, William Heinemann Limited

VII. Eisenhardt, Kathleen (1989), Building Theories from Case Study Research, Academy of Management Review, Vol 14 No 4, pp. 532 - 550

VIII. Garavan,T , O'Brien, F. and O'Hanlon, D. (2006), Career Advancement of Hotel Managers Since Graduation: a Comparative Study, Personnel Review, Vol. 35 No. 3, pp. 252-80

IX. Gilbert, D. \& Guerrier, Y. (1997), UK hospitality managers past and present, Service Industry Journal, Vol 17 (1), 115- 132

X. Glauser, B, \& Strauss, A. (1967), The Discovery of Grounded Theory: Strategies of Qualitative Research, London: Wiedenfeld and Nicholson 
XI. Gursoy, D. and Swanger,N.(2005), An industry model of hospitality curriculum for programs housed in accredited colleges of business: Part 2, Journal of Hospitality and Tourism Education, Vol 17(2), 46-54

XII. Harper S, Brown C and Wilson (2005), Qualifications: a Fast -Track to Hotel General Manager?, International Journal of Contemporary Hospitality Management, Vol. 17 No. 1,pp. 51-64.

XIII. Jansen P. , Van der Velde M. and Mul W. (2001), A Typology of Management Development, Journal of Management Development, Vol 20 No. 2, pp.106-120

XIV. Kay , C. \& Rusette , J. (2000), Hospitality - management competencies; Identifying manager's success, Cornell Hotel and Restaurant Administration Quaterly, Vol41 (2), 52-63

XV. Kay and Moncarz, (2004), knowledge, skills, and abilities for lodging management success, Cornell Hotel and Administration Quarterly, Vol 45(3), 285-298

XVI. Ladkin, A (2000), Vocational Education and Food and Beverage Experience: Issues for Career Development, International Journal of Contemporary Hospitality Management, Vol 12 No. 4, pp. 22633.

XVII. Ladkin, A and Juwaheer, T.D (2000), The Career Paths of Hotel General Managers in Mauritius, Journal of Contemporary Hospitality Management, Vol 12 No.2, pp.119-125

XVIII. Mabey C. and Thomson (2000), The Determinants of Management Development: The Views of MBA Graduates, British Journal of Management, Vol 11, pp 3-16

XIX. Mabey, C. and Thomson A. (2000), Management Development in the UK: a Provider and Participant Perspective, International Journal of Training and Development, Vol 4 No.4, pp 272- 286.

XX. Mark R. Testa*, Lori Sipe (2012), Service-leadership competencies for hospitality and tourism management, International Journal of Hospitality Management 31 (2012) 648- 658

XXI. Miles M.B and Huberman A.M (1994), "Qualitative Data Analysis - An Expanded Sourcebook", second edition, Sage Publication

XXII. Morse, J.M. and Morse, L.R. (2002), Read Me First for a User's Guide to Qualitative Methods, Sage Publications

XXIII. Rue L. W. and Byars I. (2006), Human Resource Management, Mc Graw Hill, $8^{\text {th }}$ edition.

XXIV. Strauss, A.L, and Corbin, J.M (1998), Basics of Qualitative Research: Techniques and Procedures for Developing Grounded Theory, ( $2^{\text {nd }}$ edition), Sage Publications, Thousands Oaks

XXV. Suh E., West J, Shin J. (2012), Important competency requirements for managers in the hospitality industry, Journal of Leisure, Sport \& Tourism Education, Vol 11, pp 101-112

XXVI. Thompson A.et al (2001), Changing Patterns of Management Development, Blackwell Publishing

XXVII. University of California, Berkeley (2015), Guide to Managing Human Resources, http://hrweb.berkeley.edu/guides/managing-hr/managing-successfully/development/concepts , accessed on 16 February 2016

XXVIII. Watson, S. (2008), Where are We Now?, A Review of Management Development Issues in the Hospitality and the Tourism Sector. Implications for Talent Management, International Journal of Contemporary Hospitality and Tourism Management, Vol 20 No.7, pp. 758-780

XXIX. $\quad$ WWTTC (2016), World Wide Travel and Tourism Council, available at: www.wwttc.org 